\title{
1 Calving and estrus detection in dairy cattle using a combination of indoor
}

\section{localization and accelerometer sensors}

3

4

5

6

7

8

9

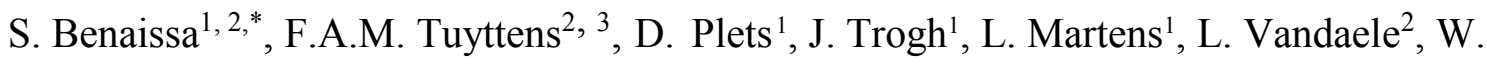
Joseph$^{1}$, B. Sonck ${ }^{3}, 4$

${ }^{1}$ Department of Information Technology, Ghent University/imec, iGent-Technologiepark 126, 9052 Ghent, Belgium

${ }^{2}$ Flanders Research Institute for Agriculture, Fisheries and Food (ILVO)- Animal Sciences Unit, Scheldeweg 68, 9090 Melle, Belgium

${ }^{3}$ Department of Nutrition, Genetics and Ethology, Faculty of Veterinary Medicine, Heidestraat 19, B-9820 Merelbeke, Belgium

${ }^{4}$ Department of Animal Sciences and Aquatic Ecology, Faculty of Bioscience Engineering, Ghent University, Coupure links 653, B-9000 Ghent, Belgium

* Corresponding author: Said Benaissa. E-mail address: said.benaissa@ugent.be Tel.: +32 09 3314908.

\begin{abstract}
Accelerometers (neck- and leg-mounted) and ultra-wide band (UWB) indoor localization sensors were combined for the detection of calving and estrus in dairy cattle. In total, 13 pregnant cows and 12 cows with successful insemination were used in this study. Data were collected two weeks before and two weeks after delivery for calving. Similarly, data were collected two weeks before and two weeks after artificial insemination (AI) for estrus. Different cow variables were extracted from the raw data (e.g., lying time, number of steps, ruminating time, travelled distance) and used to build and test the detection models. Logistic regression
\end{abstract}


models were developed for each individual sensor as well as for each combination of sensors (two or three) for both calving and estrus. Moreover, the detection performance within different time intervals $(24 \mathrm{~h}, 12 \mathrm{~h}, 8 \mathrm{~h}, 4 \mathrm{~h}$, and $2 \mathrm{~h})$ before calving and AI was investigated.

In general, for both calving and estrus, the performance of the detection within 2-4 hours was lower than for $8 \mathrm{~h}-24 \mathrm{~h}$. However, the use of a combination of sensors increased the performance for all investigated detection time intervals. For calving, similar results were obtained for the detection within $24 \mathrm{~h}, 12 \mathrm{~h}$, and $8 \mathrm{~h}$. When one sensor was used for calving detection within 248h, the localization sensor performed best (Precision (Pr) 73-77\%, Sensitivity (Se) 57-58\%, Area under curve (AUC) 90-91\%), followed by the leg-mounted accelerometer (Pr $67-77 \%$, Se $54-55 \%, \mathrm{AUC}=88-90 \%)$ and the neck-mounted accelerometer $(\operatorname{Pr} 50-53 \%, \mathrm{Se} 47-48 \%, \mathrm{AUC}=$ $86-88 \%$ ). As for calving, the results of estrus were similar for the time intervals $24 \mathrm{~h}-8 \mathrm{~h}$. In this case, similar results were obtained when using any of the three sensors separately as when combining a neck- and a leg-mounted accelerometers (Pr 86-89\%, Se 73-77\%). For both calving and estrus, the performance improved when localization was combined with either the neck- or leg-mounted accelerometer, especially for the sensitivity (73-91\%). Finally, for the detection with one sensor within a time interval of $4 \mathrm{~h}$ or $2 \mathrm{~h}$, the Pr and Se decreased to $55-65 \%$ and $42-62 \%$ for estrus and to $40-63 \%$ and $33-40 \%$ for calving. However, the combination of localization with either leg or neck-mounted accelerometer as well as the combination of the three sensors improved the Pr and Se compared to one sensor ( $\operatorname{Pr} 72-87 \%$, Se $63-85 \%)$. This study demonstrates the potential of combining different sensors in order to develop a multifunctional monitoring system for dairy cattle.

Keywords: Accelerometer, ultra-wide band (UWB) localization system, dairy cow, calving and estrus detection, precision livestock farming. 


\section{INTRODUCTION}

The profitability of dairy farms depends greatly on the reproduction efficiency of the dairy cows (Saint-Dizier and Chastant-Maillard, 2018). Therefore, timely and accurate detection of estrus and calving events are of paramount importance for farmers. To detect calving and estrus in high density livestock farms, farmer increasingly rely on automated systems using sensors (e.g., accelerometer, pedometer, pressure sensor that measures the weight of the legs, thermometer, etc.) for the collection and the interpretation of animal data. Several studies have investigated the use of sensors for calving and estrus detection in dairy cattle. For example, Jensen (2012) used a commercially available accelerometer attached to the hind leg (IceTag 3D, IceRobotics) to record changes in the number of lying bouts and in overall activity within the pre-calving period. Maltz and Antler (2007) reported that 10 out of 12 calving events were successfully detected within $24 \mathrm{~h}$ before occurrence based on an algorithm associating lying time, daily numbers of steps, and their ratio to calving moment. In another study (Zehner et al., 2019), a Naïve Bayes classifier model was used for calving prediction with an ingestive behavior monitoring device (RumiWatch noseband sensor, Agroscope, Ettenhausen, Switzerland and Itin+Hoch GmbH, Liestal, Switzerland). As a conclusion, the sensitivity (69-82\%) and specificity $(86-87 \%)$ of the predictive model were satisfying, but the positive predictive value (precision) was low (3-4\%) and the amount of false positive alerts was considerably high. In addition, activity sensors (e.g., accelerometers) were used to measure feeding and ruminating time as indicators of time of calving. Schirmann et al., (2013) documented that cows spend, on average, $63 \mathrm{~min}$ less time ruminating and $66 \mathrm{~min}$ less time feeding in the 24 -h period before calving. Ruminating and feeding time continued to decline after calving by on average 133 and $82 \mathrm{~min}$, respectively, as compared with the baseline. In another study (Borchers et al., 2017), the combination of two activity sensors (HR Tag (SCR Engineers Ltd., Netanya, Israel) and IceQube (IceRobotics Ltd., South Queensferry, United Kingdom)) for the prediction of the 
calving moment based on the neck activity, number of steps, the lying time, the standing time, and the lying bouts, yielded a sensitivity of $82.8 \%$ and a specificity of $80.4 \%$. Similarly, several studies have used a variety of sensors (activity meters, video cameras, recordings of vocalization, measurements of body temperature and milk progesterone concentration) for estrus detection (Burnett et al., 2018; Dolecheck et al., 2015; Reith and Hoy, 2018; Saint-Dizier and Chastant-Maillard, 2018; Schweinzer et al., 2019). On the basis of their review, Reith and Hoy (2018) recommended to give highest priority to the detection based on sensor-supported activity monitoring (e.g., accelerometers) as being most successful tools for automated estrus detection.

However, most research efforts and currently available systems focus on one specific function (e.g., calving or estrus) by using one sensor, which requires the farmer to buy and integrate different systems from different providers on the farm depending on the purpose. This is impractical as it increases the deployment, training, and maintenance costs. Meanwhile, the increasing availability of positioning systems based on small devices unlock the potential of using real-time animal location data for the benefit of cow and farmer. In addition to detecting multiple behaviors and activities of individual cows individual activity (e.g., lying time, drinking time, travelled distance), location data could provide information about social interactions and contacts between cows, which is relevant for assessing cow reproduction and welfare (Van Nuffel et al., 2015). Although recent studies (Homer et al., 2013; Porto et al., 2014; Tullo et al., 2016) have started to involve positioning data for the monitoring of dairy cows, localization sensors have not yet been combined with neck- and leg-mounted accelerometers for calving and estrus detection. This combination would likely increase the detection accuracy by expanding the range of predictor variables and allow automated alerting the farmer to a wider range of issues that require his action or attention as compared to systems 
based on one sensor only. Moreover, smartly combining of multiple sensors may considerably reduce the power consumption as compared to each sensor operating independently of one another. For example, when detecting a cow in lying down position by the leg-mounted accelerometer, the localization sensor could be turned-off until detecting the cow is changing position. This could save more than $50 \%$ of the energy of the position monitoring, since cows spend 12 to 14 hours per day lying down (Gomez and Cook, 2010).

In this study, ten cow variables were extracted from three sensors (a neck-mounted accelerometer, a leg-mounted accelerometer and a localization sensor). Three variables were extracted from each accelerometer (i.e., ruminating time, feeding time, and resting time from the neck-mounted accelerometer, and lying time, lying bouts, and number of steps from the legmounted accelerometer), and four variables were extracted from the localization data (i.e., travelled distance, time in cubicles, time in feeding zone, time in drinking zone). These variables were reported as good predictors for calving and/or estrus detection (Borchers et al., 2017; Jónsson et al., 2011; Rutten et al., 2017). The aim was to test and compare the performance of detecting estrus and calving using different sensors combinations for different detection time intervals $(24 \mathrm{~h}, 12 \mathrm{~h}, 8 \mathrm{~h}, 4 \mathrm{~h}$, and $2 \mathrm{~h})$ before AI and calving. This work is the first to investigate combining a neck-mounted accelerometer, a leg-mounted accelerometer, and a localization sensor for the detection of both calving and estrus events.

\section{MATERIALS AND METHODS}

2.1 Animals and housing

In total, 13 pregnant Holstein cows (parity $3.0 \pm 1.1$ ) and 12 cows (different to the pregnant cows) with successful insemination (parity $2.8 \pm 1.3$ ) were used for the detection of calving and estrus events respectively. The cows were housed with other cows (average size of the group is 
30 cows) in the free-stall barn of the Flanders Research Institute for Agriculture, Fisheries and Food (ILVO), Melle, Belgium. The barn contains four areas of $30 \mathrm{~m}$ long and $13 \mathrm{~m}$ wide each, with individual cubicles and a concrete slatted floor. The cubicles $(\mathrm{n}=32)$ were bedded with a lime-straw-water mixture. The cows were fed roughage ad libitum. The concentrates were supplied by computerized concentrate feeders. Drinking water (two troughs per group) was available ad libitum. This study was conducted between September 2017 and April 2018.

\subsection{Sensors}

Each cow was fitted with three sensors: a localization node, a leg-mounted accelerometer (right hind leg), and a collar-mounted accelerometer (Figure 1-a). For the localization data, an OpenRTLS ultra-wide band (UWB) localization system (DecaWave, Ireland) was installed in the barn using 7 anchors (including the master anchor, see Figure 2). The OpenRTLS system is built around the DW1000 chip from Decawave. This chip is able to very precisely measure the time of flight of a radio signal between a receiver and a transmitter. This results in a very accurate distance measurement which enables tagged objects to be located both indoor and outdoor. The localization measurements are based on time difference of arrival (TDoA) and Two-Way Ranging (TWR), which does not require tight synchronization between the anchors to work. The sampling rate of the localization system was set at $2 \mathrm{~Hz}$ to enable a logging interval of about 4 weeks. Accuracy measurements were performed prior to the trial proper. A localization node was put in 46 different locations in the cubicles and the alley. Then, a comparison was made between the actual locations (based on the barn map, Figure 2) and locations estimated by the localization system. The accuracy is defined as the Euclidean distance between the estimated location and the ground truth location. The mean and median accuracy were $38 \pm 8$ and $34 \pm 5$ centimeters. The precision between estimated locations of a static tag (standard deviation) was $23.1 \mathrm{~cm}$ (averaged over the 46 static locations). 
143 On the other hand, the acceleration data (i.e., 3 orthogonal accelerometer vectors) were logged 144 with a sampling rate of $10 \mathrm{~Hz}$ (10 samples each second) using Axivity AX3 loggers (Axivity

145 Ltd, Newcastle, UK). The orientation of the accelerometers is shown in Figure 1 (b-c). This orientation was respected for all cows. The clocks of the localization system and the accelerometers were synchronized at the start of data collection. We note that in the current study, the accelerometer data are stored in the loggers, but in a real deployment, these data and the localization data will be transmitted in real-time to the backend system.

$<$ Figure 1 $>$

$<$ Figure 2 $>$

\subsection{Data collection procedure}

2.3.1 Data collection for calving.

Cows were selected based on the expected calving dates using the cow calendar (date of insemination) and direct observations by ILVO trained farm staff. The pregnant cows were dried off $60 \pm 3$ days before the expected calving date and moved into the dry pen (one of the four housing areas in the barn) immediately after last milking and into the pre-partum pens (9x5 m2) 3 days before the expected calving date. No assistance was provided during calving for any of the focal cows. The sensors were attached 2 weeks before the expected day of calving and removed 2 weeks after calving. The approximate time of calving (day and hour) was recorded by the farm staff as the calf start to expel from the birth canal to the ground.

\subsubsection{Data collection for estrus.}

The sensors were attached 2 weeks before the expected day of estrus and removed 2 weeks after AI (based on the last unsuccessful insemination or the last calving day). Decisions about standing estrus were made by the ILVO trained staff. Not all inseminations were associated 
with real estruses as insemination might be performed on the basis of false alert or erroneous interpretation of a cow's behavior. Therefore, to ensure that the data-set was based on true cases of estrus, only data from periods around inseminations that led to confirmed pregnancy were used in this study. From 15 cows, 12 cows with successful insemination were used to create the dataset.

\subsection{Data processing}

The data processing was performed using MATLAB software (Release 2018b, The MathWorks, Inc., Natick, Massachusetts, United States).

\subsubsection{Processing of accelerometer data.}

In total, three variables were extracted from each accelerometer (i.e., hourly ruminating time, feeding time, and resting time from the neck-mounted accelerometer, and hourly lying time, lying bouts, and number of steps from the leg-mounted accelerometer). The data of the neckmounted accelerometer were used to obtain ruminating, feeding, and resting times based on the behavior classification algorithms presented and validated in (Benaissa et al., 2018) as follows: the sum of the time intervals of a certain behavior was considered as the time spent in this behavior (e.g., the sum of the intervals classified as ruminating was considered as ruminating time). We note here that resting behavior is when the cow has a static position (inactivity), i.e., either standing or lying. Lying bouts and lying time were extracted from the leg-mounted accelerometer as presented in (Ito et al., 2009). Finally, a simple k-Nearest Neighbors (kNN, Vázquez Diosdado et al., 2015) algorithm was developed and validated beforehand to count the number of steps based on the data of the leg-mounted accelerometer. The algorithm was validated again during the calving and estrus data collection experiments using direct observation (accuracy of $97 \%$ compared to direct observations. 
The localization data was calculated based on raw OpenRTLS UWB distance measurements between the mobile node and the fixed anchors, and a Viterbi-based tracking algorithm, a technique related to Hidden Markov Models and backward belief propagation (Trogh et al., 2015). The parameters derived from these localization data are listed in Table 1 (first two columns). The travelled distance is the sum of all distances that are labelled as walking, along the trajectory. A distance between two location updates is labelled as such if the travelled distance exceeds a threshold within a certain interval. The lower limit of this interval is to remove small jumps around the same location (as a result of location inaccuracies instead of real movement). The upper limit of this interval is to remove outliers. The threshold and the lower and upper limits of the interval are based on the time between two location updates, a maximum speed, and confidence in the measurement. The lower interval was set at $1 \mathrm{~m}$, which is sufficient to remove the influence of noise (the precision of the UWB system was $23.1 \mathrm{~cm}$ ). The upper limit is based on the time difference between two location updates and the moving speed, i.e., cows in a barn will not go faster than a maximum walking speed, e.g., $1.4 \mathrm{~m} / \mathrm{s}$ (Alsaaod et al., 2017; Chapinal et al., 2009). When a cow is located within the lying zone, e.g. the cubicles (red rectangles in Figure 2), a first timer is started. When this timer exceeds a holdoff time (i.e., 1 minute), the real lying down timer starts. The purpose of the first timer is to remove false positives (e.g., when a cow is falsely located in the boxes for a short time). The timer stops when the cow is located outside the boxes for the same hold-off time. The time at the drinking zone and feeding zone were calculated with the same procedure as time in lying cubicles but with another zone label. These zones are rectangles (or more generally polygons) that have to be specified once and can be drawn on the floor plan or defined in a text document. The default hold-off time (i.e., $1 \mathrm{~min}$ ) is the same for all zones but can be configured for each zone separately. In total, four variables were extracted from the localization data for each one- 
hour time interval (i.e., travelled distance, time in cubicles, time in feeding zone, time in drinking zone). We note that this approach based on the zones presents some limitations. For example, a cow could be standing in the cubicles and this would be recorded as lying down. Also, it is difficult to obtain reliable values of the time spent in small areas (e.g., drinking troughs).

\subsubsection{Missing localization data.}

For the two accelerometers, the data is stored on the sensors. Therefore, no accelerometer data were missing. However, the localization data contained intervals with missing values (no signal reception). A time interval (i.e., 1 hour) with localization data less than $90 \%$ was considered as a missing interval. Since the analysis requires continuous series over time, missing time intervals were imputed. The behavior of cows (e.g., travelled distance, lying time) was assumed to show a diurnal pattern as described previously (Roelofs et al., 2005). Therefore, it was assumed that a reasonable imputation could be achieved by substituting the missing data with the average of data of the same hourly interval from the previous days. As proposed in (Rutten et al., 2017), a straightforward imputation algorithm that only uses data from preceding three days was used. If data were unavailable for any of the three days, only the available days (one or two) were used. In total 350 hourly intervals (4.1\% of the total intervals) of 13 cows (calving $n=7$, estrus $n=6$ ) were imputed by the described methodology. The number of imputations ranged from 1 to 37 hourly intervals. For the collected data, no missing intervals for three consecutive days were recorded. Since the missing data were only $4.1 \%$, the imputation method did not have a large effect of the cow variables. 
237 Since the aim was to build a model for binary classification (e.g., a cow is in estrus or not), 238 logistic regression was chosen. Also, logistic regression is widely adopted when interested in the impact of various variables (variables from different sensors in this case) on a response variable (Sperandei, 2014). Logistic regression models the probability of an event based on individual variables by using the logit function given by (Sperandei, 2014):

$$
\operatorname{Logit}(p)=\ln \left(\frac{p}{p-1}\right)=a_{0}+a_{1} * X_{1}+a_{2} * X_{2}+\cdots+a_{N} * X_{N}
$$

Where $p$ indicates the probability of the event (e.g., calving), and $a_{i}$ are the regression coefficients and $X_{i}$ the model variables. From equation (1), the probability of the event is given by:

$$
p=\frac{1}{1+e^{-\left(a_{0}+a_{1} * X_{1}+a_{2} * X_{2}+\cdots+a_{N} * X_{N}\right)}}
$$

The prediction of the resulting logistic model ranges between 0 and $1(0<p<1)$ and can be interpreted as the probability that the cow is calving or in estrus. The dependent variable (i.e., event) is the binary variable "in calving" $(1=$ yes and $0=$ no). Similarly, for estrus detection, the dependent variable is "in estrus" $(1=$ yes and $0=$ no $)$. The coefficients of the regression models $\left(a_{i}\right)$ are calculated based on a training set and then used to predict the events of the testing. In this study, the data of one cow were used as testing set and the data of the remaining cows were used as training set.

\subsubsection{Model Variables.}

As described in Section 2.4, all variables (feeding time, number of steps, lying time, etc.,) were summarized in 1-h intervals. The 1-h intervals were adjusted for the actual AI (estrus) or the 
calving time ( 0 is the time of calving or AI). A 24-h moving average was applied to smooth the data as performed in (Borchers et al., 2017). To estimate the changes over time of the cow variables, each value of the calculated hourly variables $\operatorname{Var}_{\boldsymbol{i}}(\boldsymbol{t})$, with $\boldsymbol{i}$ indicates e.g., lying time, feeding time, etc. and $\boldsymbol{t}$ indicates the time interval, was subtracted from the mean value of the past 24 values of the same cow (i.e., 24 hours). The variables used for the logistic regression model (equation 2) were calculated then as follows:

$$
X_{i}(t)=\operatorname{Var}_{i}(t)-\frac{1}{24} * \sum_{k=t-24}^{k=t-1} \operatorname{Var}_{i}(k)
$$

\subsubsection{Performance Evaluation.}

The calculated variables for each 1 hour time interval as well as the labels obtained from the observation were used as inputs for the logistic regression models. Only data collected during the 7 days before calving and AI were used for the detection models (the first week was a habituation period), as the information that the event has already passed is not/less relevant. Different detection time intervals were investigated $(2,4,8,12,24$ hours $)$ as illustrated in Figure 3. For example, for $2 \mathrm{~h}$ time interval, the 2 hours before calving and AI were considered as event periods. The same was performed for 4, 8, 12, and 24h time intervals (Rutten et al., 2017; Schirmann et al., 2013). Finally, to measure the performances of the detection models, the leave-one-out cross validation strategy was used (Arlot and Celisse, 2010) to calculate the precision (Pr), the sensitivity (Se), the specificity (Sp), the overall accuracy, and the area under curve (AUC) from the ROC curve. The precision (Pr), the sensitivity (Se), and the specificity (Sp) are defined as (Chawla, 2005):

$$
\begin{aligned}
& P r=\frac{T P}{T P+F P} \\
& S e=\frac{T P}{T P+F N}
\end{aligned}
$$




$$
S p=\frac{T N}{T N+F P}
$$

280

Here, TP (true positive) is the number of instances where calving/estrus was correctly detected by the logistic regression model during the detection time interval (See Figure 3). FN (false negative) is the number of instances where no alters were generated by the model during the detection time interval. FP (false positive) is the number of alerts generated by the model before the detection time interval (i.e., non-estrus period/ before calving period). TN (true negative) is the number of instances where no alerts were generated before the detection time interval. For each case (calving and estrus), the data of one cow were used as testing set and the data of the remaining cows were used as training set. This was repeated for all cows in the data set and the average precision, sensitivity, specificity, overall accuracy, and AUC were considered.

\section{RESULTS}

\subsection{Calving}

For the neck-mounted accelerometer, the difference between the reference period and the day prior calving was highest for ruminating time (a decrease of $21 \%, \mathrm{P}<0.01$ ) followed by resting time (a decrease of $14 \%, \mathrm{P}<0.05)$, while feeding time did not change significantly $(\mathrm{P}=0.09)$ (Table 1). For the leg-mounted accelerometer, the lying bouts increased by $90 \%(\mathrm{P}<0.01)$, the number of steps increased by $71 \%(\mathrm{P}<0.01)$, but the daily lying time decreased by $28 \%$ $(\mathrm{P}<0.01)$. Finally, for the localization sensor, both the travelled distance and the time in cubicles increased by $47 \%(\mathrm{P}<0.01$ and $\mathrm{P}=0.02$, respectively). However, the time in the feeding zone decreased by $17 \%(\mathrm{P}=0.04)$ and the time in the drinking zone did not show a significant change $(\mathrm{P}>0.05)$.

\section{$<$ Table $1>$}


Table 5.2 lists the detection performance for calving for different detection time intervals (i.e., $24 \mathrm{~h}, 12 \mathrm{~h}, 8 \mathrm{~h}, 4 \mathrm{~h}$, and 2h). Similar results were obtained for the time intervals (TI) $24 \mathrm{~h}, 12 \mathrm{~h}$, and $8 \mathrm{~h}$. In the case of $24-8 \mathrm{~h}$, when one sensor was used for the detection, the localization sensor performed best $(\operatorname{Pr} 73-77 \%$, Se 57-58\%, AUC= 90-91\%), followed by the leg-mounted accelerometer $(\operatorname{Pr} 67-77 \%$, Se 54-55\%, AUC= 88-90\%) and the neck-mounted accelerometer (Pr 50-53\%, Se 47-48\%, AUC= 86-88\%). With two sensors used for the detection, the performance increased for all combinations. The best combination of two sensors was the localization with the leg-mounted accelerometer $(\operatorname{Pr} 83-84 \%$, Se $73-78 \%)$, or with the neckmounted accelerometer $(\operatorname{Pr} 82-84 \%$, Se $74-76 \%)$. Finally, the combination of three sensors yielded the highest performance ( $\operatorname{Pr} 84-88 \%$, Se 79-85\%). The specificity for all combinations was between 95 and $98 \%$.

Similar conclusions were obtained for time intervals $4 \mathrm{~h}$ and $2 \mathrm{~h}$ for the sensor combinations. However, the Pr and Se decreased to $40-63 \%$ and $33-40 \%$ for one sensor, $53-78 \%$ and $43-62 \%$ for two sensors, and $67-79 \%$ and $63-69 \%$ for three sensors. The values of the Sp were similar to TI $24-8 \mathrm{~h}$.

$<$ Table 2>

\subsection{Estrus}

For the neck-mounted accelerometer, ruminating time decreased by $26 \%(\mathrm{P}<0.01)$ between the reference period and the day of AI (Table 1). Similarly, resting time decreased by $23 \%$ $(\mathrm{P}<0.01)$. However, the $10 \%$ increase in feeding time was not significant $(\mathrm{P}>0.05)$. For the legmounted accelerometer, the lying time decreased by $38 \%(\mathrm{P}<0.01)$ and the number of steps increased by $95 \%(\mathrm{P}<0.01)$. However, the change in lying bouts was not significant $(\mathrm{P}>0.05)$. Finally, for the localization sensor, the travelled distance increased by $92 \%$ and the time in cubicles decreased by $32 \%(\mathrm{P}<0.05$ and $\mathrm{P}=0.03$, respectively). However, the time in drinking 
zone and feeding zone did not change significantly ( $\mathrm{P}=0.2, \mathrm{P}=0.1$, respectively) between the reference period and the day of AI.

Table 5.3 lists the detection performance for estrus for different detection time intervals (i.e., $24 \mathrm{~h}, 12 \mathrm{~h}, 8 \mathrm{~h}, 4 \mathrm{~h}$, and $2 \mathrm{~h}$ ). For calving, similar results were obtained for the TI $24 \mathrm{~h}-8 \mathrm{~h}$. However, the performance decreased for TI $4 \mathrm{~h}$ and $2 \mathrm{~h}$.

For TI 24h-8h, similar results were obtained when using any of the three sensors separately as when combining a neck- and a leg-mounted accelerometer ( $\operatorname{Pr} 86-89 \%$, Se 73-77\%). In these cases, the values of the Sp and AUC varied between 91 and 95\%. The performance improved when localization was combined with either the neck- or leg-mounted accelerometer, especially for the sensitivity $(85-91 \%)$. As for calving, the best performance was obtained when combining all three sensors. For TI $4 \mathrm{~h}$ and $2 \mathrm{~h}$, the $\mathrm{Pr}$ and Se decreased to $55-65 \%$ and $42-62 \%$ for one sensor as when combining a neck- and a leg-mounted accelerometer. However, the combination of localization with either leg or neck-mounted accelerometer as well as the combination of three sensors improved the $\mathrm{Pr}$ and Se compared to one sensor $(\operatorname{Pr} 72-87 \%$, Se $63-85 \%)$. The Sp and the AUC values for TI $4 \mathrm{~h}-2 \mathrm{~h}$ were similar to TI $24 \mathrm{~h}-8 \mathrm{~h}$.

$<$ Table 3>

\section{DISCUSSION}

We investigated the combination of two accelerometers (one attached to the hind leg and the other to the neck-collar) and a localization sensor for the detection of calving and estrus in dairy cattle. This would lead to the integration of different dairy cattle monitoring systems towards one multi-sensor multi-functional monitoring system. Moreover, the detection within different time intervals (24h, $12 \mathrm{~h}, 8 \mathrm{~h}, 4 \mathrm{~h}$, and $2 \mathrm{~h}$ ) before calving and AI was investigated. 
4.1 Changes in the cow variables

349 Changes were observed in most of the recorded cow variables in the 24 hours before calving 350 compared to the reference period (i.e., six days before the day of calving). The daily lying bouts and lying time was influenced by calving time, which corroborates the findings of (Jensen, 2012; Miedema et al., 2011a; Ouellet et al., 2016). In the present study, an increase of 10.4 lying bouts were found in the 24 hours before calving compared to the reference period. Our result is higher than that measured in (Ouellet et al., 2016), but comparable to two other studies that observed 7 and 7.8 more lying bouts during the last 24-h before calving compared to 4 days pre-calving, respectively (Jensen, 2012; Miedema et al., 2011a). Daily lying time decreased by 3.6 hours in the 24 hours before calving compared to the reference period. This was higher than the values $(52 \mathrm{~min} / 24 \mathrm{~h})$ reported in (Ouellet et al., 2016). The change in feeding time was not significant $(\mathrm{P}>0.05)$. This is in line with the results of (Miedema et al., 2011b), who stated that the duration of feeding did not show significant changes $(\mathrm{P}=0.09)$ during the 24 hours before calving. Ruminating time was decreased on the calving day by $21 \%$ compared with the 4 days before calving, which is comparable to $16 \%$ reported by (Schirmann et al., 2013). The variation of the results could be related to the different devices used to measure the ruminating time. (Schirmann et al., 2013) used a neck-mounted acoustic sensor, whereas a neck-mounted accelerometer was used in our study. The variation might be also due to the different housing systems. Miedema et al. (2011) housed the cows in a large straw-bedded barn, and (Jensen, 2012) kept their cows in individual calving pens, also bedded with deep straw; and (Ouellet et al., 2016) kept the cows in a tie-stall, which could explain the smaller increase in lying bouts and lying time.

Similar to calving, most of the recorded cow variables changed significantly in the 24 hours before AI. In comparison to other studies, Dolecheck et al. (2015) found that lying time decreased during the estrus period by $58 \%$. Time spent lying decreases around estrus because 
of increased activity and restlessness (Jónsson et al., 2011). This explains also the decrease of resting time. Ruminating time in our study decreased during estrus by $37 \%$. Reith and Hoy (2012) evaluated 265 estrus events, finding that ruminating time on the day of estrus decreased by $17 \%$ (74 $\mathrm{min})$, but with large variation between herds (14 to $24 \%$ ). In a follow-up study that looked at 453 estrous cycles, ruminating time decreased $20 \%(83 \mathrm{~min})$ on the day of estrus (Reith et al., 2014). Pahl et al. (2015) also found a decrease in ruminating time (19.3\%) on the day of AI. The decrease in ruminating time around estrus found in the current study $(26 \%)$ is comparable to previous studies. The change in feeding time was not significant, similar to the conclusions reported by De Silva et al. (1981), who found no change in feed intake during the 3-d period around estrus. To our knowledge, no study has used cow variables from a localization system such as time in feeding zone or time in cubicles to detect calving or estrus.

4.2 Detection with one sensor

For the detection models, with one sensor used for calving detection, the sensitivity did not exceed $68 \%$ and the precision did not exceed $77 \%$. Lower performances (i.e., a sensitivity of 21.2- 42.4\%) were also reported in (Rutten et al., 2017), where a single sensor was used for calving detection, meaning that automatic detection of calving is difficult using one sensor. The performance of estrus detection with one sensor was higher than for calving, but still lower than the combination of two or three sensors. By using a pedometer for estrus detection, (Holman et al., 2011) reported lower sensitivity (63\%) and precision (73\%) compared to a sensitivity of $77 \%$ and a precision of $92 \%$ found by the leg-mounted accelerometer in this study. In the same study, (Holman et al., 2011) reported lower sensitivity (59\%) and a similar precision (93\%) compared to the present study (77\% and $91 \%$, respectively) by using a neck-mounted accelerometer. 
2.3 Detection with a combination of sensors

When two sensors were used for detection, the best combination was leg-mounted accelerometer + localization for calving, while the best combination was neck-mounted accelerometer + localization for estrus. This could be due to the high increase of lying bouts before calving $(90 \%)$, while it did not show a significant change during estrus. Although the number of steps increased for both cases, this variable reports nearly the same information as the travelled distance reported by the localization sensor. With a combination of two accelerometers for calving detection, Borchers et al. (2017) reported high sensitivity (72-82\%) compared to the current study (62\%), which might be due to the use of a neural network algorithm compared to a logistic regression model or other factors such as the number of animals used (33 compared to 13 in this study). In a recent study by Ouellet et al. (2016), rumination time, lying time and lying bouts were recorded from two accelerometers (one on the ear tag and the other on the hind leg) and combined to predict calving events. For the detection within 24 hours before calving, Ouellet et al. (2016) found a relatively similar sensitivity to the combination of leg- and neck-mounted accelerometers in our study (57\% versus $61 \%)$, but lower specificity (57\% versus $98 \%$ ). This could be explained by the additional cow variables extracted from the accelerometers in the present study (e.g., resting time, number of steps) compared to their study. Finally, with three sensors, the precision increased to $87 \%$ for calving and $93 \%$ for estrus and the sensitivity increased to $84 \%$ for calving and $90 \%$ for estrus. The use of a combination of sensors increases the number of cow variables that could change before calving or during estrus.

For practical applications, because of the cost associated with missed events, larger specificity values are more valued in estrus detection (Rutten et al., 2017). False positives (type I errors) can cause financial losses through unnecessary AI. This is not applicable to calving prediction. Identifying a non-calving cow as calving could cause unnecessary treatment or handling. False 
negatives may be more costly with calving prediction, because systems do not detect actual calving events. The consequences of missed calving events could be extremely detrimental (e.g., dystocia, stillbirth, cow death). Therefore, if both factors cannot be concurrently obtained, calving prediction methods should be more sensitive and less specific. From a deployment point of view, in addition to the purchasing, maintenance, and processing costs, the use of a monitoring system based on one sensor that generates many false alarms elevates the costs for the farmer (e.g., wasted straws of semen, technician costs and time), frustrates the farmer, and reduces his trust in the system. On the other hand, low sensitivity leads to miss the insemination time and the imminent calving, which also decreases the reproduction efficiency of the dairy farms. Therefore, it is crucial to have an alerting system with both very high sensitivity and precision.

4.4 Influence of the detection time interval Detecting calving or estrus with one sensor was difficult for time intervals (TI) $2 \mathrm{~h}$ and $4 \mathrm{~h}$ compared to $24-8 \mathrm{~h}$. However, the combination of sensors improved the model performance for $2 \mathrm{~h}$ and $4 \mathrm{~h}$. Although the performance improved for large time intervals (24-8h), alerts two or four hours before the start of calving could be more valuable. These alerts can be seen as an indicator that calving is about to start. Alerts given eight or more hours before the start of calving may be too early, but they could be used to separate the cows. The use of multiple sensors increases the chance to detect behavioral changes within a short time frame. The use of one sensor limits the number of cow variables that can be detected by the monitoring system. Although some studies (Mattachini et al., 2013; Resheff et al., 2014) suggest that one accelerometer could detect several cow variables (Benaissa et al., 2017), not all variables are detected with the same accuracy. On the other hand, not all variables contribute meaningfully to a better detection of calving or estrus. For example, the lying bouts detected by the legmounted accelerometers and the time in feeding zone detected by the localization sensor did 
not show significant change during the estrus period. Similarly, the feeding time detected by the neck-mounted accelerometer did not change significantly before calving. Different factors such as lactation stage, environment, season, and disturbance of the cows due to diseases inspection could influence the behavior of the cows before calving or during estrus (Orihuela, 2000). For example, cattle on pasture spend more time feeding (grazing) than animals confined in barns or corrals (Phillips and Leaver, 1986) and thus have less time to engage in estrous behaviors. Gwazdauskas et al. (1983) found that the intensity of estrous behavior increased with parity, although, (Roelofs et al., 2010) stated that some secondary signs such as mounting-othercows decrease with parity.

Diseases like lameness or mastitis could also diminish cows' struts and pre-calving expressions. For instance, as shown in (Olechnowicz and Jaskowski, 2011), lame cows spent less time upright and more time lying down compared with non-lame cows during estrus. This included lame cows spending less time walking or standing. However, in that study, it is reported that lameness did not affect the durations of drinking, grazing, or ruminating, or how these behavioral states fluctuated throughout the day. Thus, a system that would be multifunctional in dairy cattle would require certainly the integration of several sensors in order to enlarge the number of cow variables detected by the monitoring system and to accommodate individual differences between cows in how they express estrus or imminent calving. Moreover, the farm management practices and human-animal interactions are widely ignored when developing systems of dairy cattle monitoring. The deployment of a multi-sensor system would decrease the impact of these factors on the detection system as it could record several cow variables.

On the other side, calving detection could be used to predict the actual day of calving which allows to move the cow to an individual pen to facilitate the surveillance and the intervention 
under good conditions of hygiene. Thus, the first prediction alert should be delivered before the second stage of parturition, because moving a cow just before or during its expulsion can extend the time of delivery (Saint-Dizier and Chastant-Maillard, 2018). A second alert should be a warning of the onset of the calf expulsion. The combination of sensor could provide alerts over different time intervals before calving, from a day $(24 \mathrm{~h})$ to a few hours, which is useful for calving management by the farmer.

The results presented in this work show clearly an improved performance, enhancing the number of successful alerts and significantly reducing the number of false alarms. Such performance with a multi-functional option is preferred by farms and the system could be deployed in large-sized dairy farms.

In addition to the cow individual activity, the use of a location system could provide information about social interactions and contacts between cows, which is important for assessing cow health and welfare (Van Nuffel et al., 2015). For example, lameness could be detected by looking at interactions between the lame cow and other cows. As lame cows have pain, they tend be lower in rank and avoid contact with other cows (Galindo et al., 2000). Social interaction between cows could also be used for estrus (e.g., mounting behavior) and calving detection (cows seek isolation from the group prior calving (Proudfoot et al., 2014).

Finally, the proposed monitoring system would require a real-time collection and wireless transfer of the UWB localization data. This severely impacts the system lifetime as energy is usually provided through batteries, which the farmer does not want to replace every few months. Ideally, the lifetime of the monitory system should match the animal's lifetime. Recently, research has been performed on the potential of wireless power transfer to power the sensors' batteries during short amounts of times when the cows are drinking or are being milked (Minnaert et al., 2018). A follow-up study with a larger sample size is required to validate the 
findings from this paper from a relatively limited set of cows and to consider different conditions (e.g., heifers, dystocia) and longer periods, as well as to include other anomalies in dairy cattle (e.g., heat stress, lameness).

\section{CONCLUSIONS}

Accelerometers (neck- and leg-mounted) and ultra-wide band (UWB) indoor localization sensors were combined for the detection of calving and estrus in dairy cattle. The detection performance within different time intervals $(24 \mathrm{~h}, 12 \mathrm{~h}, 8 \mathrm{~h}, 4 \mathrm{~h}$, and $2 \mathrm{~h})$ before calving and AI was investigated.

The performance of the detection within 2-4 hours before calving or AI was lower than for 824h. However, the use of a combination of sensors increased the performance for all investigated time intervals. For calving, similar results were obtained for the time intervals $24 \mathrm{~h}$, $12 \mathrm{~h}$, and $8 \mathrm{~h}$. In the case of $24-8 \mathrm{~h}$, when one sensor was used for detection, the localization sensor performed best (Pr 73-77\%, Se 57-58\%, AUC=90-91\%), followed by the leg-mounted accelerometer $(\operatorname{Pr} 67-77 \%$, Se 54-55\%, AUC $=88-90 \%)$ and the neck-mounted accelerometer (Pr 50-53\%, Se 47-48\%, AUC= 86-88\%). As for calving, the results of estrus were similar for the TI $24 \mathrm{~h}-8 \mathrm{~h}$. In this case, similar results were obtained when using any of the three sensors separately as when combining a neck- and a leg-mounted accelerometers (Pr 86-89\%, Se 7377\%). For both calving and estrus, the performance improved when localization was combined with either the neck- or leg-mounted accelerometer, especially for the sensitivity (73-91\%). Finally, for the detection with one sensor within TI $4 \mathrm{~h}$ and $2 \mathrm{~h}$, the $\mathrm{Pr}$ and Se decreased to 55$65 \%$ and $42-62 \%$ for estrus and to $40-63 \%$ and $33-40 \%$ for calving. However, the combination of localization with either leg or neck-mounted accelerometer as well as the combination of the three sensors improved the $\operatorname{Pr}$ and Se compared to one sensor ( $\operatorname{Pr} 72-87 \%$, Se $63-85 \%)$. This study demonstrates the potential of combining different sensors in order to develop a multi- 
functional monitoring system for dairy cattle. Future work will consist of expanding this research to other herds with larger sample size as well as considering cows' anomalies (e.g., mastitis, lameness) and other sensors (e.g., bolus or ear tag to measure the temperature).

\section{ACKNOWLEDGMENTS}

This work was executed within MoniCow, a research project bringing together academic researchers and industry partners. The MoniCow project was co-financed by imec (iMinds) and received project support from Flanders Innovation \& Entrepreneurship. The authors would like to thank Michaël De Guchtenaere and Sara Van Lembergen for their help during the measurements.

\section{REFERENCES}

Alsaaod, M., Huber, S., Beer, G., Kohler, P., Schüpbach-Regula, G., Steiner, A., 2017. Locomotion characteristics of dairy cows walking on pasture and the effect of artificial flooring systems on locomotion comfort. J. Dairy Sci. doi:10.3168/jds.2017-12760

Arlot, S., Celisse, A., 2010. A survey of cross-validation procedures for model selection. Stat. Surv. 4, 40-79. doi:10.1214/09-SS054

Benaissa, S., Tuyttens, F.A.M., Plets, D., Cattrysse, H., Martens, L., Vandaele, L., Joseph, W., Sonck, B., 2018. Classification of ingestive-related cow behaviours using RumiWatch halter and neck-mounted accelerometers. Appl. Anim. Behav. Sci. 1-8. doi:10.1016/j.applanim.2018.12.003

Benaissa, S., Tuyttens, F.A.M., Plets, D., de Pessemier, T., Trogh, J., Tanghe, E., Martens, L., Vandaele, L., Van Nuffel, A., Joseph, W., Sonck, B., 2017. On the use of on-cow accelerometers for the classification of behaviours in dairy barns. Res. Vet. Sci. doi:10.1016/j.rvsc.2017.10.005

Borchers, M.R., Chang, Y.M., Proudfoot, K.L., Wadsworth, B.A., Stone, A.E., Bewley, J.M., 2017. Machine-learning-based calving prediction from activity, lying, and ruminating behaviors in dairy cattle. J. Dairy Sci. 100, 5664-5674. doi:10.3168/jds.2016-11526

Burnett, T.A., Polsky, L., Kaur, M., Cerri, R.L.A., 2018. Effect of estrous expression on timing and failure of ovulation of Holstein dairy cows using automated activity monitors. 
Chapinal, N., de Passillé, A.M., Weary, D.M., von Keyserlingk, M.A.G., Rushen, J., 2009. Using gait score, walking speed, and lying behavior to detect hoof lesions in dairy cows. J. Dairy Sci. doi:10.3168/jds.2009-2115

Chawla, N. V, 2005. Data Mining for Imbalanced Datasets: An Overview. Data Min. Knowl. Discov. Handb. 853-867. doi:10.1007/0-387-25465-X_40

De Silva, A.W.M.V., Anderson, G.W., Gwazdauskas, F.C., McGilliard, M.L., Lineweaver, J.A., 1981. Interrelationships With Estrous Behavior and Conception in Dairy Cattle. J. Dairy Sci. doi:10.3168/jds.S0022-0302(81)82864-0

Dolecheck, K.A., Silvia, W.J., Heersche, G., Chang, Y.M., Ray, D.L., Stone, A.E., Wadsworth, B.A., Bewley, J.M., 2015. Behavioral and physiological changes around estrus events identified using multiple automated monitoring technologies. J. Dairy Sci. doi:10.3168/jds.2015-9645

Galindo, F., Broom, D.M., Jackson, P.G.G., 2000. A note on possible link between behaviour and the occurrence of lameness in dairy cows. Appl. Anim. Behav. Sci. doi:10.1016/S0168-1591(99)00114-8

Gomez, A., Cook, N.B., 2010. Time budgets of lactating dairy cattle in commercial freestall herds. J. Dairy Sci. doi:10.3168/jds.2010-3436

Gwazdauskas, F.C., Lineweaver, J.A., McGilliard, M.L., 1983. Environmental and Management Factors Affecting Estrous Activity in Dairy Cattle. J. Dairy Sci. doi:10.3168/jds.S0022-0302(83)81966-3

Holman, A., Thompson, J., Routly, J.E., Cameron, J., Jones, D.N., Grove-White, D., Smith, R.F., Dobson, H., 2011. Papers: Comparison of oestrus detection methods in dairy cattle. Vet. Rec. doi:10.1136/vr.d2344

Homer, E.M., Gao, Y., Meng, X., Dodson, A., Webb, R., Garnsworthy, P.C., 2013. Technical note: A novel approach to the detection of estrus in dairy cows using ultra-wideband technology. J. Dairy Sci. doi:10.3168/jds.2013-6747

Ito, K., Weary, D.M., von Keyserlingk, M.A.G., 2009. Lying behavior: Assessing within- and between-herd variation in free-stall-housed dairy cows. J. Dairy Sci. doi:10.3168/jds.2009-2235 
Jensen, M.B., 2012. Behaviour around the time of calving in dairy cows. Appl. Anim. Behav. Sci. 139, 195-202. doi:10.1016/j.applanim.2012.04.002

Jónsson, R., Blanke, M., Poulsen, N.K., Caponetti, F., Højsgaard, S., 2011. Oestrus detection in dairy cows from activity and lying data using on-line individual models. Comput. Electron. Agric. doi:10.1016/j.compag.2010.12.014

Maltz, E., Antler, A., 2007. A practical way to detect approaching calving of the dairy cow by a behaviour sensor, in: Proc. Precision Livestock Farming. pp. 141-146. doi:https://doi.org/10.3920/978-90-8686-604-5

Mattachini, G., Riva, E., Bisaglia, C., Pompe, J.C.A.M., Provolo, G., 2013. Methodology for quantifying the behavioral activity of dairy cows in freestall barns. J. Anim. Sci. 91, 4899-4907. doi:10.2527/jas2012-5554

Miedema, H.M., Cockram, M.S., Dwyer, C.M., Macrae, A.I., 2011a. Behavioural predictors of the start of normal and dystocic calving in dairy cows and heifers. Appl. Anim. Behav. Sci. doi:10.1016/j.applanim.2011.03.003

Miedema, H.M., Cockram, M.S., Dwyer, C.M., Macrae, A.I., 2011b. Changes in the behaviour of dairy cows during the $24 \mathrm{~h}$ before normal calving compared with behaviour during late pregnancy. Appl. Anim. Behav. Sci. doi:10.1016/j.applanim.2011.01.012

Minnaert, B., Thoen, B., Plets, D., Joseph, W., Stevens, N., 2018. Wireless energy transfer by means of inductive coupling for dairy cow health monitoring. Comput. Electron. Agric. doi:10.1016/j.compag.2018.07.010

Olechnowicz, J., Jaskowski, J.M., 2011. Behaviour of lame cows: A review. Vet. Med. (Praha). doi:10.17221/4435-VETMED

Orihuela, A., 2000. Some factors affecting the behavioural manifestation of oestrus in cattle: A review. Appl. Anim. Behav. Sci. doi:10.1016/S0168-1591(00)00139-8

Ouellet, V., Vasseur, E., Heuwieser, W., Burfeind, O., Maldague, X., Charbonneau, É., 2016. Evaluation of calving indicators measured by automated monitoring devices to predict the onset of calving in Holstein dairy cows. J. Dairy Sci. doi:10.3168/jds.2015-10057

Pahl, C., Hartung, E., Mahlkow-Nerge, K., Haeussermann, A., 2015. Feeding characteristics and rumination time of dairy cows around estrus. J. Dairy Sci. doi:10.3168/jds.20148025 
Phillips, C.J.C., Leaver, J.D., 1986. The effect of forage supplementation on the behaviour of grazing dairy cows. Appl. Anim. Behav. Sci. doi:10.1016/0168-1591(86)90116-4

Porto, S.M.C., Arcidiacono, C., Giummarra, A., Anguzza, U., Cascone, G., 2014. Localisation and identification performances of a real-time location system based on ultra wide band technology for monitoring and tracking dairy cow behaviour in a semi-open free-stall barn. Comput. Electron. Agric. doi:10.1016/j.compag.2014.08.001

Proudfoot, K.L., Jensen, M.B., Weary, D.M., von Keyserlingk, M.A.G., 2014. Dairy cows seek isolation at calving and when ill. J. Dairy Sci. doi:10.3168/jds.2013-7274

Reith, S., Brandt, H., Hoy, S., 2014. Simultaneous analysis of activity and rumination time, based on collar-mounted sensor technology, of dairy cows over the peri-estrus period. Livest. Sci. 170, 219-227. doi:10.1016/j.livsci.2014.10.013

Reith, S., Hoy, S., 2018. Review: Behavioral signs of estrus and the potential of fully automated systems for detection of estrus in dairy cattle. Animal. doi:10.1017/S1751731117001975

Reith, S., Hoy, S., 2012. Relationship between daily rumination time and estrus of dairy cows. J. Dairy Sci. doi:10.3168/jds.2012-5316

Resheff, Y.S., Rotics, S., Harel, R., Spiegel, O., Nathan, R., 2014. AcceleRater: a web application for supervised learning of behavioral modes from acceleration measurements. Mov. Ecol. 2, 27. doi:10.1186/s40462-014-0027-0

Roelofs, J., López-Gatius, F., Hunter, R.H.F., van Eerdenburg, F.J.C.M., Hanzen, C., 2010. When is a cow in estrus? Clinical and practical aspects. Theriogenology. doi:10.1016/j.theriogenology.2010.02.016

Roelofs, J.B., Van Eerdenburg, F.J.C.M., Soede, N.M., Kemp, B., 2005. Pedometer readings for estrous detection and as predictor for time of ovulation in dairy cattle. Theriogenology. doi:10.1016/j.theriogenology.2005.04.004

Rutten, C.J., Kamphuis, C., Hogeveen, H., Huijps, K., Nielen, M., Steeneveld, W., 2017. Sensor data on cow activity, rumination, and ear temperature improve prediction of the start of calving in dairy cows. Comput. Electron. Agric. doi:10.1016/j.compag.2016.11.009

Saint-Dizier, M., Chastant-Maillard, S., 2018. Potential of connected devices to optimize cattle reproduction. Theriogenology. doi:10.1016/j.theriogenology.2017.09.033 
Schirmann, K., Chapinal, N., Weary, D.M., Vickers, L., von Keyserlingk, M.A.G., 2013. Short communication: Rumination and feeding behavior before and after calving in dairy cows. J. Dairy Sci. 96, 7088-7092. doi:10.3168/jds.2013-7023

Schweinzer, V., Gusterer, E., Kanz, P., Krieger, S., Süss, D., Lidauer, L., Berger, A., Kickinger, F., Öhlschuster, M., Auer, W., Drillich, M., Iwersen, M., 2019. Evaluation of an ear-attached accelerometer for detecting estrus events in indoor housed dairy cows. Theriogenology. doi:10.1016/j.theriogenology.2019.02.038

Sperandei, S., 2014. Understanding logistic regression analysis. Biochem. Medica. doi:10.11613/BM.2014.003

Trogh, J., Plets, D., Martens, L., Joseph, W., 2015. Advanced Real-Time Indoor Tracking Based on the Viterbi Algorithm and Semantic Data. Int. J. Distrib. Sens. Networks. doi: $10.1155 / 2015 / 271818$

Tullo, E., Fontana, I., Gottardo, D., Sloth, K.H., Guarino, M., 2016. Technical note: Validation of a commercial system for the continuous and automated monitoring of dairy cow activity. J. Dairy Sci. doi:10.3168/jds.2016-11014

Van Nuffel, A., Zwertvaegher, I., Pluym, L., Van Weyenberg, S., Thorup, V.M., Pastell, M., Sonck, B., Saeys, W., 2015. Lameness detection in dairy cows: Part 1. How to distinguish between non-lame and lame cows based on differences in locomotion or behavior. Animals. doi:10.3390/ani5030387

Vázquez Diosdado, J.A., Barker, Z.E., Hodges, H.R., Amory, J.R., Croft, D.P., Bell, N.J., Codling, E.A., 2015. Classification of behaviour in housed dairy cows using an accelerometer-based activity monitoring system. Anim. Biotelemetry 3, 15 . doi:10.1186/s40317-015-0045-8

Zehner, N., Niederhauser, J.J., Schick, M., Umstatter, C., 2019. Development and validation of a predictive model for calving time based on sensor measurements of ingestive behavior in dairy cows. Comput. Electron. Agric. doi:10.1016/j.compag.2018.08.037 
664 Tables

665 Table 1. Mean values and standard error (SE) of the cow variables obtained by the three sensors for calving and estrus, [-24, 0$]$ is the 24 hours 666 before the calving moment or the AI. ( ${ }^{*} \mathrm{P}<0.05$, ${ }^{*} * \mathrm{P}<0.01$, no asterisks means $\mathrm{P}>0.05$, the MATLAB (release2018b) function ttest () was used to 667 conduct a paired-sample $t$-test). Acc: accelerometer

\begin{tabular}{|c|c|c|c|c|c|c|c|c|c|}
\hline \multirow[b]{2}{*}{ Sensors } & \multirow[b]{2}{*}{ Variables } & \multicolumn{4}{|c|}{ Calving } & \multicolumn{4}{|c|}{ Estrus } \\
\hline & & {$[-168,-24]$} & {$[-24,0]$} & Differen & & {$[-168,-24]$} & {$[-24,0]$} & Differen & \\
\hline \multirow{4}{*}{ 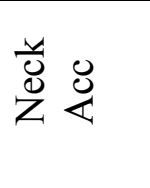 } & Ruminating time [hours] & $9.1 \pm 0.3$ & $7.2 \pm 0.4$ & $-1.9 * *$ & $-21 \%$ & $8.4 \pm 0.6$ & $6.2 \pm 0.7$ & $-2.2 * *$ & $-26 \%$ \\
\hline & Feeding time [hours] & $4.8 \pm 0.5$ & $4.3 \pm 0.3$ & -0.5 & $-10 \%$ & $4.5 \pm 0.5$ & $5.1 \pm 0.3$ & 0.6 & $13 \%$ \\
\hline & Resting time [hours] & $9.4 \pm 1.4$ & $8.1 \pm 0.6$ & $-1.3 *$ & $-14 \%$ & $7.3 \pm 0.7$ & $5.6 \pm 0.5$ & $-1.7 * *$ & $-23 \%$ \\
\hline & Lying bouts $[-]$ & $11.6 \pm 0.7$ & $22.0 \pm 1.3$ & $10.4^{* *}$ & $90 \%$ & $6.8 \pm 1.2$ & $6.1 \pm 0.8$ & -0.7 & $-10 \%$ \\
\hline \multirow{2}{*}{ 我 } & Lying time [hours] & $12.7 \pm 0.5$ & $9.1 \pm 1.2$ & $-3.6 * *$ & $-28 \%$ & $12.0 \pm 0.9$ & $7.4 \pm 1.1$ & $-4.6 * *$ & $-38 \%$ \\
\hline & Number of steps [-] & $2664 \pm 146$ & $4553 \pm 376$ & $1889 * *$ & $71 \%$ & $2470 \pm 210$ & $4824 \pm 302$ & $2354 * *$ & $95 \%$ \\
\hline \multirow{4}{*}{ 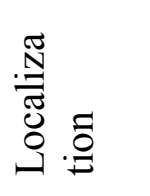 } & Travelled distance $[\mathrm{m}]$ & $2403 \pm 194$ & $3526 \pm 392$ & $1123 * *$ & $47 \%$ & $2161 \pm 165$ & $4146 \pm 285$ & $1985 * *$ & $92 \%$ \\
\hline & Time in cubicles [hours] & $8.9 \pm 0.6$ & $13.1 \pm 0.8$ & $4.2 *$ & $47 \%$ & $10.5 \pm 0.8$ & $7.1 \pm 1.0$ & $-3.4 *$ & $-32 \%$ \\
\hline & Time in feeding zone [hours] & $4.1 \pm 0.7$ & $3.4 \pm 0.9$ & $-0.7^{*}$ & $-17 \%$ & $4.8 \pm 0.5$ & $4.9 \pm 0.4$ & 0.1 & $2 \%$ \\
\hline & Time in drinking zone [min] & $16.5 \pm 11.2$ & $12.8 \pm 8.3$ & -3.7 & $-22 \%$ & $14.4 \pm 10.6$ & $19.1 \pm 13.2$ & 4.7 & $33 \%$ \\
\hline
\end{tabular}

668

$669{ }^{1}$ The difference is calculated as follows: Cow variable $([-24,0])$ - Cow variable $([-168,-24])$, and in \%: [Cow variable ([-24, 0]) - Cow variable $670([-168,-24])] /$ Cow variable $([-168,-24])$ 
Table 2. The precision (Pr), sensitivity (Se), specificity (Sp), overall accuracy (Accuracy), and AUC for calving detection using one sensor, a combination of two sensors, and a combination of the three sensors for different detection time intervals $(2,4,8,12$, and 24 hours before calving). Acc: accelerometer

\begin{tabular}{|c|c|c|c|c|c|c|}
\hline TI & $\begin{array}{l}\text { Logistic regression model } \\
\text { based on }\end{array}$ & $\operatorname{Pr}[\%]$ & $\operatorname{Se}[\%]$ & $\mathrm{Sp}[\%]$ & $\begin{array}{c}\text { Accuracy } \\
{[\%]}\end{array}$ & $\begin{array}{c}\text { AUC } \\
{[\%]} \\
\end{array}$ \\
\hline \multirow{7}{*}{$24 \mathrm{~h}$} & Neck Acc & $53 \pm 2.2$ & $48 \pm 2.5$ & $94 \pm 1.2$ & $89 \pm 0.5$ & $88 \pm 1.2$ \\
\hline & Leg Acc & $77 \pm 2.3$ & $55 \pm 2.3$ & $94 \pm 0.9$ & $90 \pm 1.2$ & $89 \pm 0.6$ \\
\hline & Localization & $77 \pm 1.8$ & $58 \pm 2.1$ & $96 \pm 0.7$ & $91 \pm 0.8$ & $91 \pm 0.4$ \\
\hline & Neck + Leg Acc & $83 \pm 1.2$ & $68 \pm 3.2$ & $98 \pm 0.5$ & $92 \pm 0.8$ & $93 \pm 0.4$ \\
\hline & Neck Acc + Localization & $82 \pm 0.9$ & $74 \pm 3.0$ & $97 \pm 0.8$ & $93 \pm 0.7$ & $94 \pm 0.5$ \\
\hline & Leg Acc + Localization & $84 \pm 0.8$ & $78 \pm 2.4$ & $97 \pm 0.8$ & $95 \pm 0.8$ & $96 \pm 0.8$ \\
\hline & All sensors & $87 \pm 1.9$ & $85 \pm 1.3$ & $98 \pm 11$ & $96 \pm 1.3$ & $97 \pm 0.9$ \\
\hline \multirow{7}{*}{$12 \mathrm{~h}$} & Neck Acc & $51 \pm 2.8$ & $47 \pm 2.9$ & $95 \pm 0.2$ & $86 \pm 0.4$ & $87 \pm 0.3$ \\
\hline & Leg Acc & $75 \pm 2.4$ & $56 \pm 1.6$ & $96 \pm 0.2$ & $91 \pm 0.3$ & $88 \pm 0.2$ \\
\hline & Localization & $77 \pm 1.6$ & $55 \pm 1.5$ & $96 \pm 0.2$ & $91 \pm 0.3$ & $90 \pm 0.5$ \\
\hline & Neck + Leg Acc & $79 \pm 1.8$ & $72 \pm 2.1$ & $96 \pm 0.3$ & $91 \pm 0.4$ & $93 \pm 0.2$ \\
\hline & Neck Acc + Localization & $84 \pm 0.9$ & $76 \pm 1.9$ & $97 \pm 0.1$ & $92 \pm 0.2$ & $94 \pm 0.1$ \\
\hline & Leg Acc + Localization & $83 \pm 0.8$ & $78 \pm 0.8$ & $95 \pm 0.4$ & $93 \pm 0.3$ & $94 \pm 0.1$ \\
\hline & All sensors & $88 \pm 1.6$ & $84 \pm 1.9$ & $98 \pm 0.2$ & $94 \pm 0.2$ & $98 \pm 0.1$ \\
\hline \multirow{7}{*}{$8 \mathrm{~h}$} & Neck Acc & $50 \pm 2.4$ & $47 \pm 2.3$ & $94 \pm 0.2$ & $87 \pm 0.3$ & $86 \pm 0.4$ \\
\hline & Leg Acc & $67 \pm 2.6$ & $54 \pm 2.5$ & $94 \pm 0.2$ & $90 \pm 0.3$ & $90 \pm 0.3$ \\
\hline & Localization & $73 \pm 1.7$ & $57 \pm 1.0$ & $93 \pm 0.3$ & $90 \pm 0.3$ & $91 \pm 0.5$ \\
\hline & Neck + Leg Acc & $73 \pm 2.0$ & $65 \pm 1.7$ & $94 \pm 0.3$ & $94 \pm 0.2$ & $94 \pm 0.2$ \\
\hline & Neck Acc + Localization & $82 \pm 0.7$ & $74 \pm 1.6$ & $96 \pm 0.1$ & $98 \pm 0.2$ & $93 \pm 0.1$ \\
\hline & Leg Acc+ Localization & $83 \pm 0.9$ & $73 \pm 1.2$ & $97 \pm 0.5$ & $97 \pm 0.2$ & $96 \pm 0.2$ \\
\hline & All sensors & $84 \pm 1.7$ & $79 \pm 2.2$ & $97 \pm 0.3$ & $97 \pm 0.5$ & $97 \pm 0.1$ \\
\hline \multirow{7}{*}{$4 \mathrm{~h}$} & Neck Acc & $47 \pm 1.9$ & $42 \pm 2.1$ & $94 \pm 0.8$ & $85 \pm 0.2$ & $83 \pm 0.5$ \\
\hline & Leg Acc & $62 \pm 1.5$ & $35 \pm 2.2$ & $94 \pm 0.5$ & $88 \pm 0.1$ & $86 \pm 0.3$ \\
\hline & Localization & $63 \pm 1.7$ & $40 \pm 2.2$ & $95 \pm 0.5$ & $89 \pm 0.2$ & $87 \pm 0.7$ \\
\hline & Neck + Leg Acc & $67 \pm 1.5$ & $54 \pm 2.0$ & $96 \pm 0.5$ & $93 \pm 0.2$ & $91 \pm 0.2$ \\
\hline & Neck Acc + Localization & $72 \pm 1.6$ & $60 \pm 1.9$ & $96 \pm 0.4$ & $94 \pm 0.1$ & $92 \pm 0.1$ \\
\hline & Leg Acc+ Localization & $78 \pm 1.0$ & $62 \pm 1.7$ & $97 \pm 0.9$ & $96 \pm 0.3$ & $94 \pm 0.3$ \\
\hline & All sensors & $79 \pm 2.1$ & $69 \pm 1.8$ & $97 \pm 0.7$ & $97 \pm 0.1$ & $94 \pm 0.1$ \\
\hline \multirow{7}{*}{$2 \mathrm{~h}$} & Neck Acc & $40 \pm 2.1$ & $39 \pm 2.2$ & $95 \pm 0.4$ & $82 \pm 0.5$ & $83 \pm 0.7$ \\
\hline & Leg Acc & $41 \pm 0.8$ & $37 \pm 2.5$ & $95 \pm 0.2$ & $86 \pm 0.5$ & $84 \pm 0.4$ \\
\hline & Localization & $43 \pm 0.7$ & $33 \pm 2.0$ & $95 \pm 0.2$ & $87 \pm 0.8$ & $86 \pm 0.9$ \\
\hline & Neck + Leg Acc & $52 \pm 0.3$ & $42 \pm 1.5$ & $95 \pm 1.0$ & $90 \pm 0.8$ & $90 \pm 0.7$ \\
\hline & Neck Acc + Localization & $56 \pm 0.4$ & $48 \pm 1.4$ & $96 \pm 0.5$ & $91 \pm 0.7$ & $92 \pm 0.2$ \\
\hline & Leg Acc+ Localization & $53 \pm 0.5$ & $43 \pm 1.9$ & $97 \pm 0.3$ & $93 \pm 0.7$ & $91 \pm 0.3$ \\
\hline & All sensors & $67 \pm 1.0$ & $63 \pm 1.0$ & $97 \pm 0.3$ & $94 \pm 0.2$ & $92 \pm 0.4$ \\
\hline
\end{tabular}


680

681

682

683

Table 3. The precision (Pr), sensitivity (Se), specificity (Sp), overall accuracy (Accuracy), and AUC for estrus detection using one sensor, a combination of two sensors, and a combination of the three sensors for different detection time intervals $(2,4,8,12$, and 24 hours before AI). Acc: accelerometer

\begin{tabular}{|c|c|c|c|c|c|c|}
\hline TI & $\begin{array}{l}\text { Logistic regression model } \\
\text { based on }\end{array}$ & $\operatorname{Pr}[\%]$ & $\mathrm{Se}[\%]$ & $\mathrm{Sp}[\%]$ & $\begin{array}{c}\text { Accuracy } \\
{[\%]}\end{array}$ & $\mathrm{AUC}[\%]$ \\
\hline \multirow{7}{*}{$24 \mathrm{~h}$} & Neck Acc & $88 \pm 1.8$ & $76 \pm 1.1$ & $93 \pm 0.8$ & $95 \pm 0.2$ & $93 \pm 0.8$ \\
\hline & Leg Acc & $89 \pm 2.4$ & $77 \pm 1.5$ & $93 \pm 0.4$ & $95 \pm 0.3$ & $94 \pm 0.2$ \\
\hline & Localization & $89 \pm 2.0$ & $75 \pm 0.9$ & $94 \pm 0.8$ & $94 \pm 0.8$ & $93 \pm 0.5$ \\
\hline & Neck + Leg Acc & $89 \pm 2.9$ & $77 \pm 1.7$ & $95 \pm 0.8$ & $95 \pm 0.5$ & $93 \pm 0.6$ \\
\hline & Neck Acc + Localization & $91 \pm 3.2$ & $88 \pm 1.9$ & $98 \pm 0.5$ & $96 \pm 0.4$ & $97 \pm 0.4$ \\
\hline & Leg Acc + Localization & $92 \pm 1.3$ & $89 \pm 2.4$ & $98 \pm 0.2$ & $96 \pm 0.4$ & $97 \pm 0.7$ \\
\hline & All sensors & $93 \pm 1.4$ & $90 \pm 1.2$ & $99 \pm 0.3$ & $98 \pm 0.3$ & $99 \pm 0.2$ \\
\hline \multirow{7}{*}{$12 \mathrm{~h}$} & Neck Acc & $87 \pm 0.8$ & $75 \pm 2.1$ & $93 \pm 0.1$ & $94 \pm 0.3$ & $91 \pm 0.4$ \\
\hline & Leg Acc & $87 \pm 0.9$ & $76 \pm 2.3$ & $92 \pm 0.2$ & $93 \pm 0.1$ & $91 \pm 0.1$ \\
\hline & Localization & $86 \pm 1.0$ & $78 \pm 2.4$ & $93 \pm 0.5$ & $96 \pm 0.1$ & $92 \pm 0.4$ \\
\hline & Neck + Leg Acc & $87 \pm 1.5$ & $78 \pm 1.9$ & $95 \pm 0.5$ & $97 \pm 0.1$ & $93 \pm 0.1$ \\
\hline & Neck Acc + Localization & $90 \pm 2.1$ & $89 \pm 2.0$ & $98 \pm 0.1$ & $97 \pm 0.3$ & $95 \pm 0.6$ \\
\hline & Leg Acc + Localization & $91 \pm 2.0$ & $91 \pm 1.3$ & $98 \pm 0.8$ & $99 \pm 0.1$ & $96 \pm 0.2$ \\
\hline & All sensors & $91 \pm 2.4$ & $90 \pm 2.3$ & $99 \pm 0.8$ & $99 \pm 0.1$ & $96 \pm 0.1$ \\
\hline \multirow{7}{*}{$8 \mathrm{~h}$} & Neck Acc & $87 \pm 0.7$ & $74 \pm 2.4$ & $94 \pm 0.5$ & $93 \pm 0.3$ & $92 \pm 0.2$ \\
\hline & Leg Acc & $86 \pm 0.9$ & $73 \pm 2.2$ & $95 \pm 0.3$ & $94 \pm 0.1$ & $91 \pm 0.1$ \\
\hline & Localization & $87 \pm 2.3$ & $76 \pm 2.8$ & $93 \pm 0.2$ & $93 \pm 0.3$ & $92 \pm 0.5$ \\
\hline & Neck + Leg Acc & $86 \pm 0.7$ & $74 \pm 2.7$ & $94 \pm 0.1$ & $96 \pm 0.1$ & $92 \pm 0.1$ \\
\hline & Neck Acc + Localization & $90 \pm 2.5$ & $85 \pm 2.0$ & $94 \pm 0.3$ & $97 \pm 0.5$ & $94 \pm 0.6$ \\
\hline & Leg Acc+ Localization & $91 \pm 2.3$ & $90 \pm 1.8$ & $97 \pm 0.1$ & $97 \pm 0.1$ & $92 \pm 0.1$ \\
\hline & All sensors & $92 \pm 2.3$ & $91 \pm 1.7$ & $98 \pm 0.2$ & $98 \pm 0.2$ & $97 \pm 0.4$ \\
\hline \multirow{7}{*}{$4 \mathrm{~h}$} & Neck Acc & $64 \pm 1.5$ & $54 \pm 2.7$ & $94 \pm 0.3$ & $93 \pm 0.2$ & $90 \pm 0.4$ \\
\hline & Leg Acc & $65 \pm 1.4$ & $51 \pm 2.8$ & $95 \pm 0.1$ & $92 \pm 0.1$ & $91 \pm 0.1$ \\
\hline & Localization & $64 \pm 1.7$ & $57 \pm 2.6$ & $94 \pm 0.2$ & $94 \pm 0.2$ & $92 \pm 0.1$ \\
\hline & Neck + Leg Acc & $68 \pm 2.0$ & $62 \pm 2.2$ & $95 \pm 0.3$ & $93 \pm 0.1$ & $92 \pm 0.1$ \\
\hline & Neck Acc + Localization & $79 \pm 2.4$ & $76 \pm 2.4$ & $95 \pm 0.2$ & $94 \pm 0.4$ & $94 \pm 0.8$ \\
\hline & Leg Acc+ Localization & $79 \pm 2.6$ & $75 \pm 2.6$ & $98 \pm 0.3$ & $95 \pm 0.1$ & $95 \pm 0.2$ \\
\hline & All sensors & $87 \pm 2.3$ & $85 \pm 2.7$ & $97 \pm 0.1$ & $95 \pm 0.1$ & $95 \pm 0.1$ \\
\hline \multirow{7}{*}{$2 \mathrm{~h}$} & Neck Acc & $58 \pm 2.4$ & $42 \pm 2.8$ & $95 \pm 0.2$ & $91 \pm 0.1$ & $90 \pm 0.5$ \\
\hline & Leg Acc & $58 \pm 2.3$ & $55 \pm 2.5$ & $95 \pm 0.3$ & $90 \pm 0.1$ & $90 \pm 0.1$ \\
\hline & Localization & $59 \pm 2.4$ & $56 \pm 2.5$ & $94 \pm 0.5$ & $93 \pm 0.1$ & $91 \pm 0.3$ \\
\hline & Neck + Leg Acc & $55 \pm 2.6$ & $58 \pm 2.0$ & $96 \pm 0.4$ & $92 \pm 0.2$ & $93 \pm 0.5$ \\
\hline & Neck Acc + Localization & $72 \pm 2.0$ & $63 \pm 2.3$ & $94 \pm 0.5$ & $95 \pm 0.2$ & $93 \pm 0.5$ \\
\hline & Leg Acc + Localization & $72 \pm 2.7$ & $63 \pm 1.9$ & $97 \pm 0.6$ & $94 \pm 0.1$ & $94 \pm 0.4$ \\
\hline & All sensors & $78 \pm 2.1$ & $71 \pm 2.7$ & $97 \pm 0.8$ & $94 \pm 0.1$ & $94 \pm 0.5$ \\
\hline
\end{tabular}


686 Figure 1. A cow wearing the three sensors (a) and the orientation of the neck- and legmounted accelerometers ( $\mathrm{b}$ and $\mathrm{c})$. $\mathrm{X}, \mathrm{Y}$, and $\mathrm{Z}$ are the axes of the accelerometers

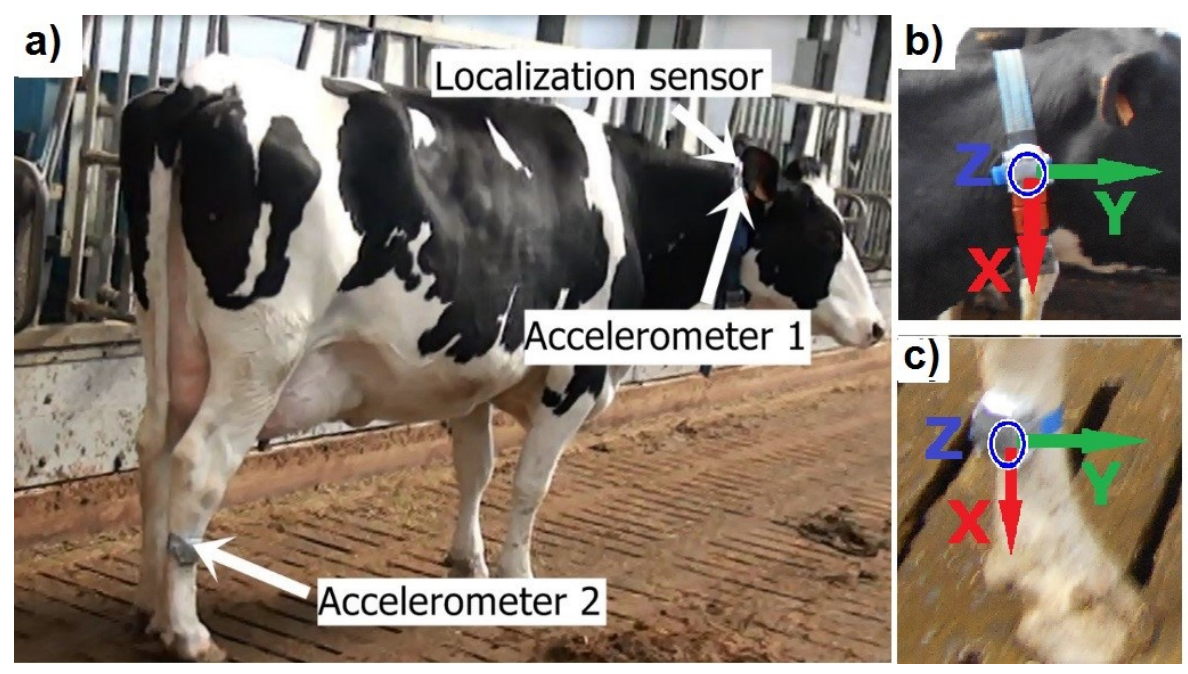

689

690 
Figure 2: Localization defined zones (red: lying zone, green: drinking zone, yellow: feeding zone and concentrate feeders). The black circles are the locations of the anchors

693

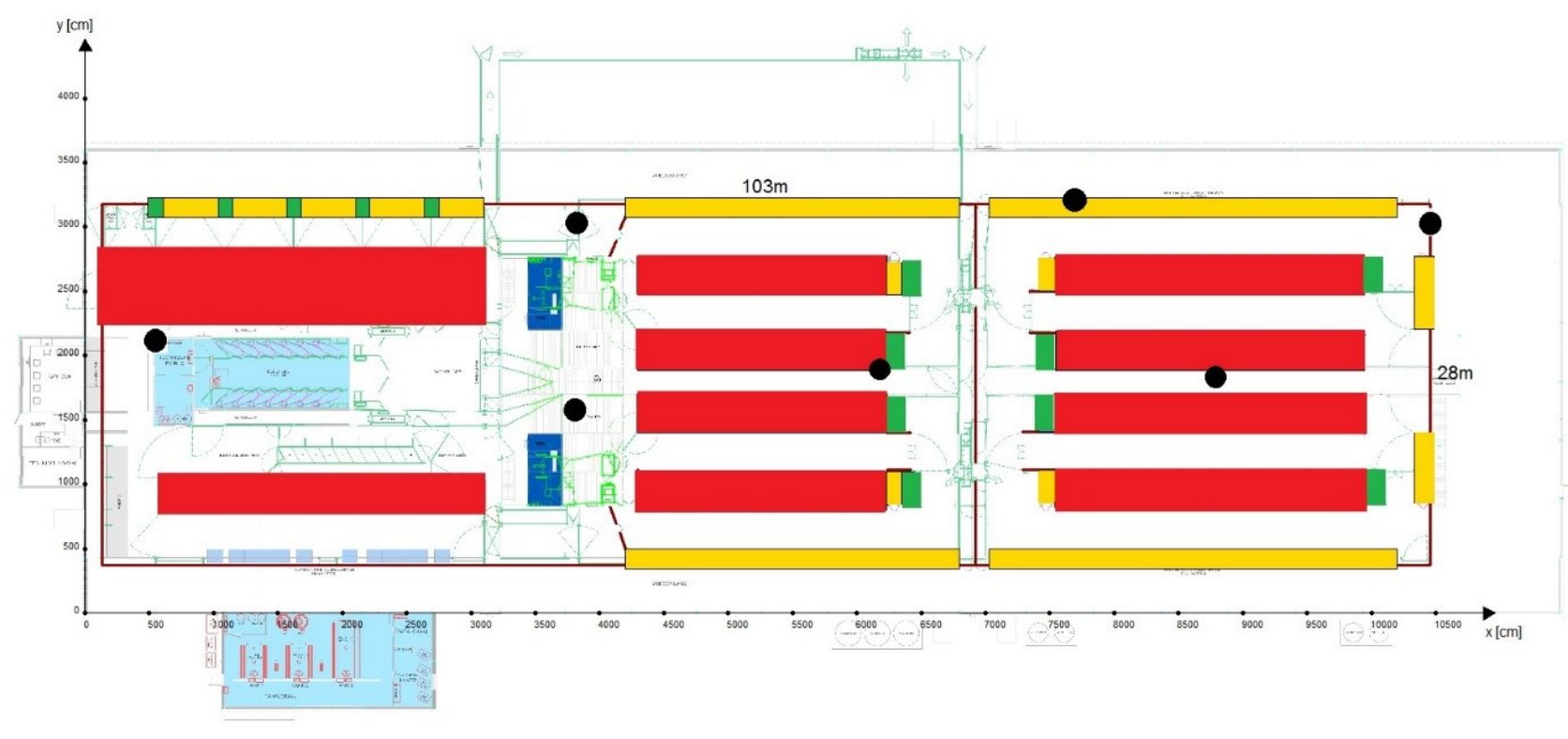

694

695

696

697 
698 Figure 3. Association between generated alerts or not generated alerts with the performance 699 evaluation: True positive (TP), True negative (TN), False positive (FP), and False negative 700 (FN). The red line indicates the calving time and the artificial insimination time (estrus).

701

Detection time interval

$(2,4,8,12,24 h)$

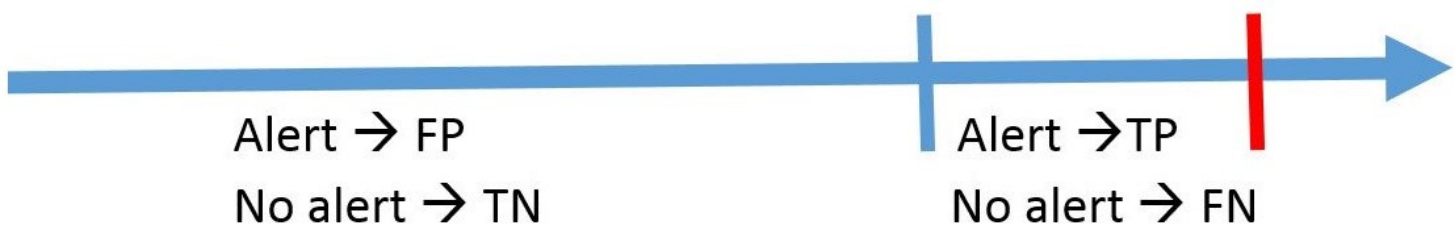

702

703

704

705

706 